\title{
TEMAS CAPITAIS DA EDUCAÇÃO A DISTÂNCIA Nós e Entrenós que tecem a Rede da Formação de Professores
}

\author{
Capital themes of distance education \\ We and between us that form the tail of teacher's formation
}

Rosália Maria Ribeiro de Aragão ${ }^{1}$
Sheila Costa Vilhena Pinheiro

\section{RESUMO}

Neste trabalho comunicamos um estudo decorrente de uma investigação qualitativa na modalidade narrativa que se funda em experiências formativas vividas durante interações em aulas de uma disciplina de fundamentos da educação a distância, integrante de um curso piloto de especialização para a formação de professores-tutores de ciências e matemáticas. Essa disciplina foi desenvolvida por três formadoras, dentre as quais a pesquisadora se inclui, em quatro turmas de alunos-professores de ciências e matemáticas no ensino fundamental, na educação infantil e nas séries iniciais. Dentre esses alunos-professores apenas 05 (cinco) de cada uma das quatro turmas, figuram como sujeitos desta pesquisa, selecionados a partir do maior nível e freqüência de reflexividade dos seus relatos autobiográficos. Nesta investigação objetivamos explicitar os saberes produzidos no processo de formação tutorial-docente passíveis de dar referência à construção de práticas diferentes e diferenciadas de formação docente a distância. A mobilização desses saberes foi acompanhada por meio de diários-debordo e de memoriais elaborados pelos alunos-professores, bem como de anotações pessoais de campo registradas in procesu durante dois ciclos de cinco dias, nos turnos da manhã e tarde. Os dados obtidos foram tratados em função de temáticas emergentes, expressas neste estudo em termos que incidem sobre 'paradigma', 'mudança', 'avaliação' e 'afetividade', pela consideração de importância que os sujeitos atribuíram a diferentes questões no âmbito da Educação a Distância, considerando a sua relevância no contexto educacional do tempo presente. A análise desses dados revela que, na ausência de situações reais, a reflexão sobre práticas simuladas que ensejam problemas autênticos da aprendizagem e da formação a distância pode mobilizar a produção de saberes vinculada à proposição de práticas formativas atualizadas e inovadoras no âmbito da Educação a Distância. Tais saberes são atinentes à compreensão dessa modalidade educativa com base em um paradigma emergente. Nesse sentido, o preconceito em relação a EAD torna-se passível de ser superado em função da garantia do desenvolvimento de outras/novas possibilidades formativas, através dessa modalidade, que impliquem concepções teórico-metodológicas e epistemológicas diferenciadas em termos de perspectiva paradigmática, formação, avaliação.

Palavras-chave: Educação a Distância, Formação Docente, Temas Capitais.

\footnotetext{
${ }^{1}$ Docente-Pesquisadora do Programa de Pós-Graduação em Educação em Ciências e Matemáticas (PPGECM/UFPa).

2 Professora de Ciências e Biologia, Especialista em Ensino de Ciências e Mestre em Educação em Ciências.

AMAZÔNIA - Revista de Educação em Ciências e Matemáticas V.6 - n. 11 - jul. 2009/dez. 2009, V. 6 - n. 12 - jan 2010/jun. 2010
} 


\begin{abstract}
This paper comunicates a research that is fruit of a qualitative and narrative investigation based on experiences during the discipline fundamentals of distance education, part of an especialization course of science and mathematics teachers. This discipline was developed by three teachers, including the researcher, in four classes of students-teachers of science and mathematics at fundamental teach, kids' education and inicial series. Between those subjects, only 5 (five) of one of each class, are subjects of this research, selected from the bigger level of frequency of reflexibility in their autobiography. In this investigation, we aimed to explain the knowledge produced during the formation process, giving reference to the construction of diferente practices of distance formation. ; the mobilization of these knowledges was accomplished through diaries and memories elaborated by the student - teachers, besides that, personal things written and registred in procesu during two cicles of five days, in the morning and in the afternoon. The data incide above the paradigm, change, for the importance that the subjects gave to diferent questions to the distance education, considering the relevance in the educational contexto nowadays. The analyse of those reveals lack of real situations, practical reflexions that influence authentic learning problems and the distance formation to mobilize the production of the knowledge related to the proposition of formative practices in distance education. Those problems related to Distance education is passive of being developed other possibilities, thorough this option that implie diferente conceptions in therms of perspective, formation and avaliation.
\end{abstract}

Key-words: distance education, teacher's formation, capital themes.

\title{
INTRODUÇÃO
}

É na perspectiva de uma construção coletiva que edificamos nossos ideais de uma educação sem distância, traduzida no que chamamos de estar junto pedagógico, ou seja, na possibilidade de viver - na relação professor-aluno que é encetada - os princípios da acessibilidade, do diálogo, da interação, da não-excludência e da afetividade.

Paradoxalmente, ao longo do tempo e de diferentes modos, vamos constatando a existência de um campo fértil a essa educação sem distância (e, portanto, ao trabalho coletivo) no âmbito da Educação a Distância, justamente porque percebemos que os princípios que fundamentam o estar junto pedagógico, a que nos referimos anteriormente, estão fortemente presentes em seu contexto.

Esses aspectos se fazem presentes no processo de ensino a distância porque, embora condição básica para a auto-aprendizagem seja a natureza adulta, autônoma, autodiretiva e

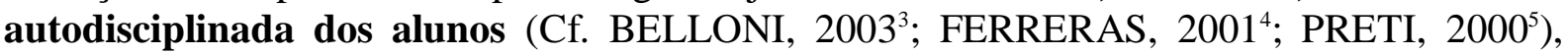
esses aprendizes sentem forte necessidade de interagir, para compartilhar experiências, conhecimentos, dificuldades e/ou 'tirar dúvidas', quer com professores quer com outros alunos. Enfim, os sujeitos envolvidos em processos educativos/formativos a distância desejam sentir-se junto de alguém, apesar da distância física - e às vezes temporal - que os separa.

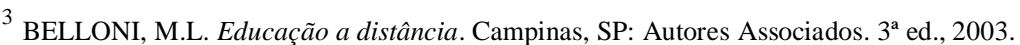

4 FERRERAS, E.R. Presencia de la educación a distancia. Puerto Rico: Publicaciones Puertorriqueñas, 2001.

5 PRETI, O. Autonomia do Aprendiz na Educação a Distância: significados e dimensões. In: PRETI, 2000. O. (Org.) Educação a Distância: construindo significados. Cuiabá: NEAD/IE - UFMT; Brasília: Plano, 2000.
} 
Nesses termos, a educação a distância é, certamente, uma alternativa ao sistema de ensino presencial, o qual já não consegue atender, de forma isolada, a uma demanda crescente de jovens e adultos, que enfrentam problemas criados pelo tempo ou as distâncias para dar continuidade em sua formação escolar ou acadêmica, (MONTEIRO, 2005:08) ${ }^{6}$. Em função disso, essa modalidade de ensino está se ampliando, e com isso, vem enfrentando seu maior desafio nesse processo de expansão que é o de conquistar progressiva qualidade na relação ensino-aprendizagem.

A conquista de qualidade no processo educacional a distância implica investimentos em pesquisas e profissionais qualificados neste segmento, os quais possam se dedicar para ousar metodologicamente nos termos de um ensino que vise a construção efetiva de conhecimentos. Profissionais que coloquem suas competências a serviço de criar e inovar em recursos comunicacionais, projetar ações de interação, ou seja, produzir mais e melhores condições para o estabelecimento do estar junto pedagógico como circunstância promissora de uma educação sem distâncias, embora os sujeitos desse processo estejam situados num espaço-tempo diferentes.

Nosso País, e particularmente a região Amazônica, vive hoje uma grande demanda por qualificação docente de formação superior, em busca de atender às exigências da Lei de Diretrizes e Bases da Educação (LDBEN 9.394/96). Em geral, são professores leigos em busca de realizar cursos de graduação nas áreas de ensino. Em função da sobrecarga de trabalho que esses profissionais enfrentam diariamente torna-se, efetivamente, difícil conciliar seu tempo restrito com as configurações da modalidade de ensino presencial, daí porque uma parcela considerável desses profissionais tem optado pelo sistema de ensino a distância.

Escolha como essa tem sido feita também por outros profissionais da educação, já com formação superior, que desejam realizar cursos de aperfeiçoamento e de pós-graduação. Tal quadro explica o porquê das instituições formadoras estarem apostando altos investimentos em programas de formação inicial e continuada de professores tendo como via a Educação a Distância.

Chegamos a essas constatações ao nos embrenharmos no contexto de ação de um programa de formação continuada e de certificação de professores de Ciências e Matemáticas ${ }^{7}$ que atuam na educação infantil e no ensino fundamental, adotando para esse fim o sistema de ensino a distância. Das experiências nesse contexto formativo emergiram os temas capitais que sistematizamos nesse estudo.

\section{Por uma compreensão do Contexto e das nossas Intenções de Pesquisa}

Nesta comunicação tornamos público um estudo de natureza qualitativa, na modalidade de investigação narrativa, que incide sobre as experiências formativas em uma prática de educação continuada docente no âmbito do referido programa de formação docente, que desenvolve suas ações no contexto da Educação a Distância. Tais experiências envolveram professores de ciências e matemáticas que participavam de um curso para a Formação de Tutores em nível de especialização.

Esse curso de Formação de Tutores, em caráter semi-presencial, foi desenvolvido no Pólo do Baixo Tocantins, reunindo, após prévia seleção, professores dos municípios de Abaetetuba, Concórdia do Pará, Bujaru, Limoeiro do Ajuru, Moju e Igarapé-Miri, atuantes nas áreas de Educação Matemática e Científica. Sendo uma iniciativa piloto do programa, o

\footnotetext{
${ }^{6}$ MONTEIRO, P. Expansão da EAD segue Tendência Mundial. Guia de Educação a Distância. Rio de Janeiro. Ano 2, nº 2, 2005.

7 Refiro-me ao Programa 'EDUCIMAT': Formação, Tecnologia e Serviços em Educação em Ciências e Matemáticas' do NPADC/UFPA. 
curso serviu, igualmente, para "testar" a qualidade dos módulos produzidos pelos formadoresautores, estes também envolvidos com a formação tutorial.

As atividades presenciais do curso foram realizadas no município de Abaetetuba, sede do Pólo da região do Baixo Tocantins, inicialmente, com duas turmas: (1) Educação Matemática e (2) Educação em Ciências e Matemáticas para a Educação Infantil e, posteriormente, em duas novas turmas (3) Educação em Ciências e (4) Educação em Ciências e Matemáticas para as Séries Iniciais.

O cenário investigativo configurou-se no âmbito das interações em aula de uma disciplina de Fundamentos da Educação a Distância, correspondente ao módulo de mesma abordagem, ministrada nas quatro turmas referidas. Tal dinâmica interativa, proporcionada em meio a debates e trocas de experiências, trouxe à tona diversas questões de natureza reflexiva que foram emergindo como resultado da apropriação daqueles alunos-professores sobre as problemáticas da Educação a Distância, algumas das quais destacamos neste estudo:

A presencialidade afiança o 'estar junto pedagógico' no sentido máximo de parceria que a expressão sugere?

\section{Diante da necessidade da mudança no ensino a distância, qual direção tomar?}

A distância espaço-temporal é um obstáculo instransponível ao 'estar junto pedagógico' na relação ensino-aprendizagem?

\section{É possivel avaliar processualmente estando ao longe?}

Essas e outras questões fluíram reiteradamente na dinâmica de debates internos em todas as turmas, trazendo à tona assuntos polêmicos sobre a prática de formação de professores a distância. Temáticas que foram se constituindo impasses, questões que causavam desconforto, ora dentre os alunos-professores, ora entre estes e os formadores e, inclusive, entre as próprias formadoras.

Diante disso, optamos por adjetivar esses assuntos polêmicos de temas capitais, justamente porque incidem sobre questões cruciais da Educação a Distância, revelando pontos de vista muito semelhantes ou convergentes, mas também discordantes ou divergentes. Temas que apontam em várias direções, mas também confluem para uma direção primordial: a busca da qualidade da ação/formação docente e, em primeira instância, do sucesso do sistema educacional brasileiro.

Essa pluralidade temática instigou-nos o desejo crescente de traçar um fio investigativo, problematizante, que pudesse estabelecer o maior número de interrelações possíveis - que denominamos de 'entrenós' - em torno de temas capitais da Educação a Distância - denominado 'nós' - que emergiram em momentos cruciais de discussão naquele contexto. Configura, assim, os assuntos envoltos em uma atmosfera de polêmica e, como não poderia deixar de ser, de fascinação.

Pensamos que a ação de problematizar a própria prática no contexto da formação a distância desencadeia um processo reflexivo próprio (Cf. Dewey citado por ZEICHNER, $1993^{8}$ ) em busca de possíveis respostas para as questões inicialmente postas, mas, sobretudo, para a configuração do objeto desta pesquisa, uma vez que, segundo Nóvoa $(1992: 25)^{9}$, não se trata de mobilizar a experiência apenas numa dimensão pedagógica, mas também num quadro conceptual de produção de saberes.

\footnotetext{
${ }^{8}$ ZEICHNER, K. A formação reflexiva de professores: idéias e práticas. Lisboa: Educa, 1993.

${ }^{9}$ NÓVOA, 1995. A. (Org.) Os professores e a sua formação. Portugal: Lisboa, Publicações Dom Quixote. $2^{\mathrm{a}}$ ed. (Coleção Temas de Educação) 
Assim, para poder enxergar o "fio que costura a teia", detivemos nosso olhar na multiplicidade de determinação daquele processo, para compreender como aqueles grupos se posicionam e se desenvolvem frente a questões que demandam conflito, polêmicas que causam desconforto mútuo. Além disso, intencionávamos também compreender como esses grupos buscavam, também, sugerir novas possibilidades de proposições, reflexões, idéias e escolhas, com o propósito de construir coletivamente um perfil próprio de ação. Em outras palavras, buscamos compreender como traduzem seus conhecimentos explícitos ou tácitos na construção de uma prática de formação de professores a distância(CHAVES, 2000:12) ${ }^{10}$.

Aquele contexto plural, no qual incide a formação de professores, se revelou um campo fecundo para essa finalidade, pois reuniu formadoras e alunos-professores, cada qual com suas trajetórias pessoais, profissionais e acadêmicas diferentes, que aproximavam também diferentes cenários da Amazônia. Desse modo, permitiu-nos refletir sobre o processo de formação de professores a distância a partir das diversas distâncias educacionais amazônicas e, ao invés de copiar outras práticas, construir uma prática própria, ao invés de receber idéias prontas, questionar e refletir, ao invés de adotar modelos prontos, propor novos e outros modelos, situando-nos, no dizer de Chaves (2000:12), como sujeitos-objetos de construção de uma prática de formação, de professores de ciências e matemática a distância.

Diante dessas questões, a pesquisa que delineamos foi se configurando tendo como questão fundante a seguinte:

Que saberes foram produzidos nos processos vivenciados - em termos presenciais e semi-presenciais - que podem servir de balizadores para a construção de uma epistemologia da prática de formação de professores de ciências e matemáticas a distância?

Trazer à luz, dar transparência, explicitar possíveis respostas para essas questões a partir das experiências interativas vividas no âmbito de um curso piloto de especialização para a formação de professores-tutores de ações de ensino e de aprendizagem/formação a distância, se tornou o objeto/objetivo de pesquisa por nós perseguido.

\section{Nossas Opções Metodológicas}

Fomos ao encontro da Investigação Narrativa, como conduta de expressão e de investigação, por acreditar que seu potencial holístico pode servir ao propósito de comunicar quem somos, que fazemos, como nos sentimos e porque devemos seguir certo curso de ação e não outro (McEWAN e EGAN, 1995:21) ${ }^{11}$.

Isto nos levou a compreender que a reflexão implica a imersão consciente do homem no mundo de sua experiência (PEREZ GÓMES, 1992:103) ${ }^{12}$. Por isso, optamos por tornar a referida experiência prática com a formação de tutores para a EAD, o contexto no qual obtivemos o material empírico que nos serviu de argamassa para a construção dos 'dados e das informações' que constituem esta investigação-narrativa.

Nessa perspectiva, a narrativa se confirma como uma abordagem lingüística e cognitiva adequada para nos propiciar referência de estruturação e sistematização de fatos e idéias neste estudo. Isto porque esta abordagem em seu cunho investigativo se apresenta como uma possibilidade de apreender, a partir da valorização das vozes dos sujeitos pertencentes ao

\footnotetext{
10 CHAVES, S.N. A Construção Coletiva de uma Prática de Formação de Professores de Ciências: tensões entre o pensar e o agir. Campinas, SP. Universidade Estadual de Campinas, Faculdade de Educação, 2000. (Tese de Doutorado)

11 McEWAN e EGAN, H., K. La Narrativa en la Enseñanza, el aprendizaje y la investigación. Argentina: Amorrortur editores, 1995.

12 PEREZ GÓMEZ, A. O Pensamento Prático do Professor: a formação do professor como profissional reflexivo. In NÓVOA, A. (Org.) Os professores e a sua formação. Portugal: Lisboa, Publicações Dom Quixote. $2^{\mathrm{a}}$ ed., 1992. 
contexto sob análise, conforme McEwan e Egan (1995:15), o que há por trás das aparências exteriores do comportamento humano para explorar sentimentos, pensamentos e intenções dos seus agentes.

Os encontros diários da disciplina piloto na prática de EAD enfocada, que corresponderam a 40 horas-aula em cada uma das quatro turmas do curso de especialização de tutores, a que referimos anteriormente, constituíram o campo fértil de onde obtivemos as vozes que valorizamos neste estudo. Essas vozes foram por nós tratadas na forma de episódios narrativos, isto é, de 'vozes' imbricadas em falas, relatos e experiências, passíveis de comunicar os sentidos que os sujeitos atribuem a realidade por eles vivida (Cf. CARNIATTO e ARAGÃO, 2003:02) ${ }^{13}$.

Capturamos essas vozes em diários de bordo produzidos pelos alunos-professores ao final de cada encontro, em memoriais entregues por eles no encerramento da disciplina, bem como por anotações de campo feitas durante aquele processo continuado de ensino e pesquisa.

Inicialmente, a disciplina se desenvolveu em duas das turmas iniciais - (1) de Educação Matemática e (2) Educação em Ciências e Matemáticas para a Educação Infantil e, posteriormente, em outras duas turmas - (3) de Educação em Ciências e (4) Educação em Ciências e Matemática para Séries Iniciais.

A condição de interatividade presente nos encontros da disciplina enfocada, nas várias turmas do curso, tornou-se favorável ao processo de ebulição de idéias, pensamentos e reflexões que emergiram nas vozes daqueles sujeitos - alunos-professores e formadoras ao explicitarem seus receios, suas dúvidas, seus preconceitos, suas críticas e esperanças com relação à formação docente justamente na consideração da modalidade de educação a distância.

Tal dinâmica revelou pontos de vista convergentes e divergentes entre os alunosprofessores, entre estes e as formadoras e, inclusive, das formadoras entre si, marcando momentos tensos de discussão, em torno de questões polêmicas pertinentes à complexidade do processo de ensino a distância.

Em função das inúmeras leituras que fizemos a partir das fontes de registros daquela experiência prática confirmamos nossa impressão inicial de que tais questões reincidiam nas quatro turmas do curso, embora variassem em nível de interesse e discussão atribuídos por esta ou aquela turma. Assim, a problemática manifesta evidenciou-se, para nós, como questões cruciais da educação a distância, dados os termos de consideração de sua relevância per se, bem como dada a importância educacional que os sujeitos lhes atribuíram. Resolvi, pois, denominá-las temas capitais.

Sendo assim, decidimos construir, a partir dos temas capitais que emergiram nas discussões e conflitos no contexto de interação cognitiva, vividos pelos sujeitos coparticipantes da experiência prática de formação docente sob análise, um objeto de investigação multifacetado feito de questões cruciais - denominadas nós - que podem representar tanto impasses quanto as necessárias amarras, mas que ajudam a tecer uma rede de relações - entrenós - entre conhecimentos práticos e teóricos, ali confrontados e reconstruídos.

Os sujeitos que figuram neste estudo foram selecionados entre os alunos-professores que produziram todos os relatos solicitados e com maior frequiência reflexiva. Desse modo,

\footnotetext{
${ }^{13}$ CARNIATTO e ARAGÃO, I.;R.M.R. de. Investigação Narrativa: Uma Possibilidade para a Pesquisa em Ensino segundo o Paradigma da Complexidade. Anais do IV ENPEC. Águas de Lindóia, São Paulo, 2003.
} 
figuram como sujeitos estruturais desta pesquisa aqueles que estão presentes na organização da coleta de dados e informações, justamente porque atendem aos atributos criteriais de seleção que adotamos. Entretanto, vale anunciar que, vez por outra, estão incluídos no corpo do texto as falas de sujeitos conjunturais que, dada a importância do que dizem para a discussão, serão momentaneamente recrutados.

Desse modo, entre as falas que figuram neste relato, estão as de $\mathbf{2 0}$ alunosprofessores registradas principalmente em diários e memoriais, em função das quais consideramos a possibilidade de expressar termos vários de pluralidade e de diferença como características singulares daquela experiência. Além deles, estão presentes as falas das formadoras responsáveis pela disciplina, as quais foram registradas em minhas anotações de campo.

Ao intensificar, pois, nossa imersão no material empírico obtido e organizado, detivemos nossa atenção na consideração das recorrências, da reiteração dos pontos de vista e reflexões que convergem entre os atores com os quais dialoguei, quer entre os alunosprofessores que conviveram naquele contexto prático e entre as formadoras, quer entre as práticas às quais tivemos acesso. A partir disso, empenhamo-nos igualmente em explicitar, de um lado, as divergências e contradições de idéias e posições e, de outro lado, na observação das comunalidades, isto é, daquilo que os diferentes grupos de sujeitos traziam em comum em suas falas e que, por esse motivo, se imbricam ao que lhes é peculiar.

Como resultantes desses critérios estabelecidos, a partir do material de pesquisa, definimos no contexto desse estudo quatro temas capitais expressos em palavras eloqüentes e significativas: (1) mudança (2) paradigma (3) avaliação, (4) preconceito. Esses temas capitais vieram à tona reiteradamente naquela experiência formativa, razão pela qual os destacamos, considerando que eles traduzem eloqüentemente a dinâmica daquele contexto prático.

Resolvemos tratar esses temas/problemas/questões pelo delineamento de três temas mais abrangentes e inclusivos, em função de episódios narrativos, de forma a ensejar discussões expressivas e significativas. Os temas constituem, portanto, as análises que tecemos a seguir.

\section{Uma Direção para a Mudança}

O aluno-professor Wan demonstra considerar que o projeto de mudança passa pela construção de uma nova postura docente, tendo em vista novas formas de ensino - presencial ou a distância - bastante diferentes, mas ainda indefinidos com relação à sua estrutura e organização. Para Siqueira (2004:197) ${ }^{14}$, dessas formas novas de aprendizagem e de autoeducação poderá nascer a nova escola que irá se consolidar até a metade do século 21, em especial no Brasil .

Esse autor nos esclarece que para construir a nova escola não basta reunir toda a parafernália eletrônica e colocá-la dentro de uma escola (Ib.Ibid.:189), pois o sofisticado aparato tecnológico pode esconder a mais tradicional forma, memorística e alienante, de ensinar a obedecer mecanicamente. Acima de tudo, a nova escola tende a ser aquela construída e reconstruída pelo novo professor, daí porque a necessidade de investir em sua formação ao longo da vida, através de oportunidades formativas presenciais e a distância.

\footnotetext{
${ }^{14}$ SIQUEIRA, E. 2015: Como Viveremos. São Paulo: Saraiva, 2004.
} 
Frente ao desafio de projetar uma 'nova escola' a distância e construir em si um 'novo professor', os sujeitos desta pesquisa viveram, a nosso ver, o que foi sua maior crise/conflito: conceber um outro/novo processo educacional a distância sendo possuidores de concepções educacionais enraizadas no ensino presencial, de caráter tradicional. Essa foi uma das maiores dificuldades manifestadas nos depoimentos, tal como no de Rose: ...preciso deixar de lado o que está muito forte no professor presencial que é a forma mecânica de transmitir informações referente a resquícios deixados pela educação tradicional.

A origem do conflito de Rose parece situar-se num confronto interno, no qual ela põe em questão sua própria prática docente presencial, de caráter tradicional, que estaria deixando-lhe insatisfeita. Rose demonstra compreender que hoje, ensinar a distância, não significa simplesmente transpor, de maneira automática, as práticas tradicionais do ensino presencial para materiais impressos, áudios, vídeos ou ambientes virtuais de aprendizagem a distância.

A abordagem tradicional da educação a distância, entre outros aspectos, parece resultar de um movimento, quase automático, de simples transposição do ensino presencial de caráter transmissivo - para um ensino a distância também nestes termos. Essa questão está presente no seguinte depoimento conjuntural: Penso que ensinar a distância é direcionar informações através de textos, pela internet ou livros, onde a pessoa que está a aprender só recebe para se desenvolver de acordo com as informações que lhes são oferecidas, mas sem a presença do professor.

A aluna-professora Edsel também demonstra ter entendido o processo nessa direção, quando diz: Busco entender como se fazer essa educação tendo como 'clientela' alunos ainda 'dependentes' da presença do professor, muitas vezes sem iniciativa ou sem traços de autonomia. Tanto na manifestação anterior quanto na de Edsel é possível perceber que esses sujeitos parecem acreditar na transposição automática de um ensino para o outro.

A restrição do potencial pedagógico da EAD vincula-se ao fato dessas percepções estarem associadas a concepções conservadoras de educação e de 'educação a distância'. Isso porque, entre outros aspectos, admitem a mercantilização do conhecimento/informação como um simples bem de consumo, produzido em série e embalado em pacotes instrucionais.

Partindo do pressuposto de que os sujeitos desta pesquisa, apesar de estarem em formação para atuar a distância, ainda olham essa alternativa de educação em função do contexto do ensino presencial, é possível inferir que Edsel, ao considerar os alunos ainda 'dependentes' da presença do professor, muitas vezes sem iniciativa ou sem traços de autonomia, está se referindo a características usuais dos alunos da educação presencial.

Entretanto, é imprescindível considerar que a educação a distância corresponde a uma outra modalidade educativa que, embora possa estar apoiada em alguns dos suportes teóricoepistemológicos do ensino presencial, demanda outras abordagens metodológicas, outras competências docentes, outro perfil de aluno e, conseqüientemente, outras/novas relações pedagógicas, diferentes ou diferenciadas da presencial.

De algum modo, Edsel parece estar vivendo um momento de conflito em busca desse entendimento, pois se vê confusa entre o contexto do ensino presencial, de caráter conservador e alunos dependentes, e a projeção de um ensino a distância que supere as práticas tradicionais e promova a aprendizagem autônoma. Essa situação pode ser bastante positiva se considerarmos que é impossível aprender sem ficar confuso (SCHÖN, 1992:85) ${ }^{15}$,

\footnotetext{
${ }^{15}$ SCHÖN, D. Formar professores como profissionais reflexivos. In: NÓVOA, 1995, A. (Org.) Os professores e a sua formação. Portugal: Lisboa, Publicações Dom Quixote. 2 2a ed., 1992. 
o que está relacionado às incertezas advindas de um processo de mudança, em que o grande inimigo é a resposta que se assume como verdade única.

No processo de busca por caminhos e respostas, Edsel vive um conflito que incorpora, de algum modo, o desafio de superar na educação a distância a dimensão reprodutivista, da individualidade acrítica favorecida pelo vislumbramento do indivíduo frente à modelagem de belas verdades (PRETI, 2000a:29) ${ }^{16}$, tendo em vista o propósito da construção de sujeitos sociais coletivos.

A aluna-professora Dani manifesta ter compreendido essa questão ao dizer que atualmente, a transição de paradigmas pela qual a sociedade passa, também influencia no modo de ver a educação como um todo, o que poderá proporcionar relativas mudanças na prática de programas com a EAD.

O conceito de paradigma proposto por Morin $(1996)^{17}$ com base na noção de relação possibilita que conceitos e teorias soberanos possam coexistir e conviver com teorias adversárias, ampliando o conceito excludente de Khun, e reconhecendo que as mudanças paradigmáticas convivem, simultaneamente, com outras experiências, teorias, outros conceitos ou fenômenos recalcitrantes que não se ajustam facilmente ao paradigma vigente (MORAES, 1997:32) ${ }^{18}$. Acreditamos que esse enfoque conceitual se ajusta mais adequadamente ao corpo deste relato.

Ao se referir a uma transição de paradigmas, Dani demonstra compreender que a mudança pode estar ocorrendo apenas no âmbito das práticas pedagógicas, presenciais ou a distância, mas estas também podem ser resultado ou estar relacionada a transformações de dimensões mais amplas, situadas no nível do paradigma. Nessa perspectiva, a educação, de modo geral, passa por um processo de transição no qual coexistem e competem diferentes concepções paradigmáticas, e isso gera reflexos em várias direções, inclusive na EAD.

Esse processo de transição paradigmática se instaura num movimento de insatisfação frente a concepções teórico-metodológico e epistemológicas que já não satisfazem mais as exigências da sociedade neste século, fato que gera instabilidade, incertezas, dúvidas e provisoriedade, pois desencadeia e impulsiona um processo de mudança. Nesse processo uma questão central se põe para os sujeitos: Em que direções pode/deve se estabelecer a mudança?

Vale ressaltar que, em função de uma história já construída, a Educação a Distância congrega hoje uma diversidade de concepções teóricas, metodológicas e epistemológicas coexistentes, que vão do fordismo ${ }^{19}$ à aprendizagem aberta e flexível ${ }^{20}$. Esse fato constitui um quadro no qual é possível fazer um paralelo entre as influências do paradigma conservador ${ }^{21} \mathrm{e}$ de um paradigma emergente nesse contexto educacional.

\footnotetext{
16 PRETI, O. Educação a Distância e Globalização: desafios e significados. In: PRETI, O. (Org.) Educação a Distância: construindo significados. Cuiabá: NEAD/IE - UFMT; Brasília: Plano, 2000a.

17 MORIN, E. Epistemologia da Complexidade. In: SCHNITMAN, 1996.D.F. (Org.). Novos Paradigmas, cultura e subjetividade. Porto Alegre: Artmed, 1996.

18 MORAES, M.C. O Paradigma Educacional Emergente. Campinas, SP: Papirus. (Coleção Práxis), 1997.

19 Belloni (2003:14-19) descreve a abordagem de EAD inspirada no modelo fordista de produção industrial nos seguintes termos gerais: forma industrializada de educação a serviço da expansão da oferta, vinculada a um grande provedor especializado, produzindo um ensino estandardizado para um mercado de massa, com forte inspiração behaviourista, divisão acentuada do trabalho, racionalização, produção em massa de "pacotes educacionais", concentração e centralização da produção e burocratização. Para essa autora, es se modelo tem provocado a desqualificação dos quadros acadêmicos e técnicos ("alienados" em processos de trabalho fragmentados e estandardizados, desumanização do ensino com a mediação e a burocratização das tarefas de ensino e aprendizagem).

20 Belloni (2003) caracteriza, em linhas gerais, a Aprendizagem Aberta (AA) do seguinte modo: ênfase na demanda (preocupação com as necessidades específicas e com meios necessários para atender às diferentes demandas); ensino centralizado no aprendente, flexibilidade de gestão dos processos, diversificação da oferta, ênfase nos critérios de qualidade, ênfase na interação em rede, inspiração construtivista.

21 No corpo deste relato faço uso as expressões paradigma conservador e paradigma tradicional como similares.
} 
É preciso, pois, considerar que as práticas pedagógicas, presenciais e a distância, carregam de modo subjacente um modelo de educação e de escola que têm por base um conjunto de teorias do conhecimento. Em outras palavras, a abordagem educacional empregada em qualquer contexto histórico e cultural é influenciada e determinada pelo paradigma da ciência que predomina na sociedade (Cf. MORAES, 1997).

As concepções de ensino que sustentam uma abordagem tradicional de EAD centramse em ações de instrução que são levadas ao aprendiz-aluno que as assimila e reelabora $e$ volta ao centro provedor de informações (NISKIER, 1999:612) ${ }^{22}$, através de técnicas de autoinstrução. Esse tipo de abordagem educativa, de caráter instrucional, configura uma visão conservadora de ensino-aprendizagem, pois se apresenta em modelos condutivistas de aprendizagem que estão a serviço da transmissão (repasse) e memorização de fatos e informações descontextualizadas.

Particularmente, no contexto da EAD, esses pacotes instrucionais, tidos como autosuficientes, descrevem todos os passos que o aluno deve percorrer para concluir com êxito o curso (MANSUR, 2001:41)23. Reúnem um grande volume e variedade de informações descontextualizadas sobre fatos isolados e verdades inquestionáveis, dispostos em materiais impressos, programas de áudio e vídeo, em softwares vários - do tipo exercício-e-prática ou drill-and-practice, tutoriais, jogos e alguns simuladores - ou em ambientes virtuais de aprendizagem (AA) que prestam unicamente para os alunos "baixarem" arquivos de apostilas.

$\mathrm{Na}$ feição convencional ou na computacional, apesar de algumas "vantagens" com relação aos tecnologicamente atrativos, esses programas continuam sendo a expressão das tradicionais práticas de ensino decorrentes da visão mecanicista de mundo e de homem, que envolvem e reforçam a repetição e a memorização de informações. Esse paradigma de ensino tradicional tem prevalecido em larga escala em situações de aprendizagem presenciais ou a distância, e se mantém em detrimento do desenvolvimento de processos educacionais mais significativos, não lineares, criativos e complexos de natureza formativa.

Justamente por essas e outras razões, as influências do paradigma dominante na educação já não atendem hoje as expectativas de um processo de ensino-aprendizagem de qualidade, fato que provoca insatisfação e desencadeia um movimento de busca por outras/novas explicações conceituais e concepções acerca dos fenômenos educacionais. Essa questão se explicita na assertiva da aluna-professora Rose: Se quisermos uma educação de qualidade é necessário que, como sociedade, mudemos alguns conceitos de educação.

Para Rose, as concepções de educação que prevalecem hoje já não correspondem aos parâmetros de uma educação de qualidade, daí porque ela reconhece e destaca a necessidade de mudá-las. De modo similar, os fundamentos teóricos do paradigma científico dominante, atualmente, se tornam cada vez mais incapazes de propor soluções para os problemas que pressionam a sociedade.

Santos (2005:41-42) ${ }^{24}$ ressalta que a crise do paradigma dominante resulta do enorme avanço no conhecimento que ele mesmo propiciou, ou seja, os limites e as insuficiências estruturais desse paradigma foram percebidos na medida em que o aprofundamento do conhecimento permitiu ver a fragilidade dos pilares em que se funda.

Foram alguns indícios, sinais da influência de paradigmas inovadores e emergentes, que os sujeitos desta pesquisa discutiram em busca de uma educação, particularmente no

\footnotetext{
${ }^{22}$ NISKIER, A. Educação a Distância: a tecnologia da esperança. São Paulo, SP: Edições Loyola. 2a ed., 1999.

${ }^{23}$ MANSUR, A. A Gestão na Educação a Distância: novas propostas, novas questões. In: LITWIN, 2001. E. (Org.) Educação a Distância: temas para o debate de uma nova agenda educativa. Porto Alegre: Artmed. Tradução de Fátima Murad, 2001.

${ }^{24}$ SANTOS, B.S. Um Discurso sobre as Ciências. $3^{\mathrm{a}}$ ed. São Paulo: Cortez, 2005.
} 
âmbito da modalidade a distância, que pudesse equacionar o que vem acontecendo no cenário científico, com a necessidade premente da construção e da reconstrução das pessoas e do mundo contemporâneo (OLIVEIRA, 2003:30) ${ }^{25}$.

Tendo em vista a superação da visão mecanicista derivada do paradigma cartesianonewtoniano, o desafio que se apresentou foi o de conceber/projetar sínteses de uma outra/nova proposta educacional, nos termos do que propõe Moraes (1997:18):

...centrada na pessoa, que compreenda a importância do pensar crítico e criativo, que seja capaz de integrar as colaborações das inteligências humanas e da inteligência da máquina, lembrando, no entando, que só o ser humano é capaz de transcender e criar.

No contexto dos debates sobre a necessidade do uso de tecnologias na educação a distância, a aluna-professora Drica demonstrou perceber que a sociedade tecnológica constitui um cenário em que há espaço para uma diversidade de abordagens educativas, daí porque assim afirma: Acredito que outras formas de ensinar são válidas, principalmente na sociedade em que estamos inseridos, repleta de recursos tecnológicos.

Ao situar-se na sociedade tecnológica, Drica expressa seu entendimento de que, nesse contexto, a modalidade presencial pode coexistir com a EAD e com outras formas de ensinar, caracterizando um cenário onde há espaço para a pluralidade de métodos de ensino e de abordagens pedagógicas, desenvolvidos através de enfoques abertos e colaborativos, em perspectivas inter e transdisciplinares.

\section{Avaliação da Aprendizagem na Educação a Distância}

A avaliação da aprendizagem é, indiscutivelmente, uma questão imperiosa na prática educativa. Essa, certamente, é a razão pela qual os sujeitos desta pesquisa a valorizaram como um assunto capaz de suscitar polêmicas, como algo que lhes provocou/provoca, continuadamente, preocupações, dúvidas, inquietações, desejo de mudança e necessidade de buscar novos caminhos.

Ao considerar e admitir a complexidade da questão da avaliação da aprendizagem manifestamos necessidade de estabelecer uma demarcação conceitual mais nítida daquilo que assumimos, neste relato, como avaliação. Assim, compartilhamos do pensamento de Sacristán $(1998: 265)^{26}$, segundo o qual a avaliação se constitui como uma dimensão da prática pedagógica e, como tal, incorre sobre todos os elementos da relação ensino-aprendizagem.

Nesse sentido, a avaliação se explica pelo modo como são realizadas as funções que a instituição educativa desempenha, razão pela qual a prática avaliativa é condicionada por inúmeros e variados elementos pessoais, sociais e institucionais. Assim, as práticas avaliativas e as idéias que as orientam, podem revelar as bases teórico-metodológicas e epistemológicas que lhes estão subjacentes nas diferentes situações de ensino-aprendizagem.

Nos primeiros momentos de discussão, percebemos que os alunos-professores mantinham uma certa tendência a potencializar as dificuldades e os problemas envolvidos na avaliação, particularmente, quando tentavam compreendê-la sob o ponto de vista da educação a distância. Essa manifestação inicial parece estar presente no desabafo de Drica: Sei que a avaliação da aprendizagem é, realmente, um assunto muito polêmico porque é algo que nos angustia demais... principalmente, na EAD.

\footnotetext{
${ }^{25}$ OLIVEIRA, E.G. Educação a Distância na Transição Paradigmática. Campinas, SP: Papirus, 2003.

${ }^{26}$ SACRISTÁN, J.G. A Avaliação no Ensino. In: SACRISTÁN e PÉREZ GóMEZ, J.G. e A.I. Compreender e Transformar o Ensino.

Tradução de Ernani F. da Fonseca Rosa. 4a ed. Porto Alegre: Artmed, 1998.
} 
A aluna-professora Drica demonstra um sentimento de angústia, um mal-estar (Cf. ESTEVES, 1998 $)^{27}$ que é usual entre os professores quando estes se vêem inseridos em debates que focalizam, sobretudo, o processo de avaliação educacional (VASCONCELLOS, $2005)^{28}$. É possível que esse sentimento esteja vinculado a uma situação de instabilidade, gerada quando os professores se vêem diante das inúmeras controvérsias como as que têm marcado idéias e ações pertinentes a avaliação da aprendizagem do aluno.

Álvares Méndez (2002:68) ${ }^{29}$ enuncia uma questão paradoxal e conceitualmente conflitiva da avaliação que surge em meio à profusão de funções, misturada num jogo desordenado no qual confunde-se qualidade com quantidade, a profissão docente com o ofício de vigilante e selecionador social, a formação docente com a preparação para a instrução. Esse autor considera que, como resultado dessa miscelânea, instala-se a confusão conceitual e a inconsistência prática.

Para Vasconcellos $(2002)^{30}$ a contradição presente nas práticas avaliativas é provocada pela inadequação de métodos em relação aos objetivos propostos. Esse descompasso, certamente, está vinculado à falta de precisão na definição do foco da avaliação, isto porque, com freqüência, os critérios e instrumentos avaliativos adotados são incompatíveis com o que se pretende avaliar em termos de conteúdos de ensino, quer conceituais, quer processuais ou procedimentais e mesmo atitudinais. Resulta daí uma tensão permanente entre aquilo que se quer avaliar e o que se faz para alcançar esse intento.

Os sujeitos manifestaram a crença de que a situação não-convencional da relação ensino-aprendizagem a distância tende a agravar as dificuldades do processo de avaliação da aprendizagem. Cabe lembrar que a questão dessas dificuldades per se tem se revelado, nos últimos tempos, sobremaneira problemática no âmbito da educação e da formação presencial (Cf. ESTEBAN, 2001 ${ }^{31}$; HOFFMANN, 2004 $4^{32}$; 2005; VASCONCELLOS, 2002; ÁLVARES MÉNDEZ, 2002; MORETTO, 2001 ${ }^{33}$; SALINAS, 2004 ${ }^{34}$ ).

Esse entendimento revela preconceitos e falta de clareza a respeito das especificidades e reais possibilidades ofertadas pela EAD. Além disso, representa o risco de transformar essa modalidade educativa num contexto capaz de reunir e agravar todos os males da educação convencional em termos presenciais. Segundo essa perspectiva equivocada, a saída para a Educação a Distância seria aproximar-se, o máximo possível, da lógica que orienta a educação presencial, a despeito do desgaste quase insustentável que esta sofre.

Essa questão se evidencia no que diz a aluna-professora Val sobre como entende, em termos comparativos a avaliação da aprendizagem nas duas modalidades: Para a avaliação na EAD funcionar tão bem quanto numa sala de aula, só mesmo se ela for presencial. Ao considerar que a avaliação na educação a distância somente pode ter êxito se for presencial, a aluna-professora condiciona, em maior ou menor medida, a educação a distância ao parâmetro

\footnotetext{
${ }^{27}$ ESTEVE, J.M. Mudanças Sociais e Função Docente In NÓVOA, 1998. A.(Org.). Profissão Professor. Portugal, Lisboa: Porto . $2^{\mathrm{a}}$ ed., 1998.

${ }^{28}$ VASCONCELLOS, C. dos S. A avaliação e o desafio da aprendizagem e do desenvolvimento humano. Pátio, Ano IX, nº 34. mai/jul, 2005.

29 ÁLVARES MÉNDEZ, J.M. Avaliar para conhecer, examinar para excluir. Tradução de Magda Schwartzhaupt Chaves. Porto Alegre: Artmed, 2002.

${ }^{30}$ VASCONCELLOS, M.M.M. Avaliação e Ética. Londrina: UEL, 2002.

${ }^{31}$ ESTEBAN, M.T. A Avaliação no Cotidiano Escolar. In: ESTEBAN, 2001. M.T. (Org.) Avaliação: uma prática em busca de novos sentidos. $3^{\mathrm{a}}$ ed., Rio de Janeiro: DP\&A, 2001.

${ }^{32}$ HOFFMANN, J.M.L. Avaliação: mito e desafio: uma perspectiva construtivista. Porto Alegre: Mediação. $34^{a}$ ed., 2004.

${ }^{33}$ MORETTO, V.P. Prova: um momento privilegiado de estudo — não um acerto de contas. Rio de Janeiro: DP\&A, 2001.

${ }^{34}$ SALINAS, D. Prova Amanhã !: a avaliação entre a teoria e a realidade. Tradução de Magna Schwartzhaup Chaves. Porto Alegre:
} 
da educação presencial, como parâmetro de veracidade. Só parece ter "valor de verdade" o que é feito em termos factuais, presenciais.

O que emerge de crenças e posições como essas que Val demonstra, por um lado, é o desconhecimento das especificidades, quer de comunalidades quer de diferenças, do contexto pedagógico da EAD em relação ao presencial usual. Por outro lado, ela manifesta, claramente, a crença de que, na distância, são mantidas as mesmas condições de ensino e aprendizagem que, tradicionalmente, se mantêm na educação presencial, cujas práticas avaliativas envolvem, entre outros critérios de cunho positivista, o controle, a objetividade e o sentido punitivo pela "não-aprendizagem". Tais aspectos são, justamente, à luz do pensamento positivista, alguns dos atributos de "qualidade" das práticas pedagógicas mais eficientes.

De ambos os lados, no entanto, essa compreensão evidencia uma postura preconceituosa em relação a educação a distância. Isso porque encerra uma tendência a desqualificar a avaliação nessa modalidade de ensino, sob o argumento de que, se esta não ocorrer, exclusivamente, nos moldes do ensino presencial, então, não há como ser digna de credibilidade.

A ênfase nos exames presenciais e seus resultados, ao final do processo, reduz a prática avaliativa a observações pontuais do aprendiz, apenas em situações programadas. Desse modo, a avaliação da aprendizagem assume uma função comparativa e classificatória, de veredicto, que subestima ou nega a importância das relações dinâmicas necessárias à construção do conhecimento, solidificando lacunas de aprendizagem (HOFFMAN, 2005:62 $)^{35}$. Em outras palavras, mantém-se irrelevante a consideração de importância atribuída ao que o aluno está desenvolvendo ao longo de todo o seu processo de aprendizagem/formação a distância.

Álvares Méndez (2002:35) nos alerta, ainda, que a ênfase no exame acaba valorizando, no decorrer do processo, justamente aquilo que será cobrado do aluno, em detrimento do que, realmente, vale a pena aprender e ter o seu valor reconhecido. Nessa perspectiva, assinala o autor, parece que só vale a pena dedicar tempo e esforço àquilo que é visto como objeto de controle. O interesse em aprender é outra questão, e o valor intrínseco dos conteúdos de aprendizagem fica à margem.

Essa perspectiva restringe o papel da avaliação à realização de tarefas discretas, descontínuas, isoladas, insignificantes em seu isolamento, transformando-a em apêndice do ensino. Tende, pois, a assumir o pensamento de Álvares Mendes (2002:17), segundo o qual a ênfase em avaliar somente no final, ou por unidade de tempo ou de conteúdo, é chegar tarde para garantir a aprendizagem contínua e oportuna.

Uma abordagem avaliativa dessa natureza está associada à idéia que privilegia a mensuração por testes padronizados, favorecendo a chamada educação de massas (Cf. VASCONCELLOS, 2002), numa perspectiva usualmente assumida pelas abordagens tradicionais e conservadoras de Educação a Distância.

A nosso ver, no contexto da educação a distância, uma concepção avaliativa com ênfase em exames presenciais e seus resultados, no sistema de médias, estatísticas, índices numéricos, não está a serviço da aprendizagem a distância em seu processo de desenvolvimento. Mesmo porque, tal como considera Aragão $(2002: 18)^{36}$, a aplicação de

\footnotetext{
35 HOFFMANN, J.M.L. Avaliação Mediadora: uma prática em construção da pré-escola à universidade. Porto Alegre: $24^{\mathrm{a}}$ ed., 2005.

36 ARAGÃO, R.M.R. de. Aspectos Teórico-Metodológicos Fundamentais para Compreender a Dimensão Processual do Ensino em Cursos Profissionais Universitários de Graduação. In: ARAGÃO, R.M.R. et. all. Tratando da Indissociabilidade Ensino-Pesquisa-Extensão. São Bernardo do Campo: UMESP, 2002.
} 
TEMAS CAPITAIS DA EDUCAÇÃO A DISTÂNCIA: Nós e Entrenós que tecem a Rede da Formação de Professores - Rosália Maria Ribeiro de Aragão, Sheila Costa Vilhena Pinheiro

"exames", em larga escala, se restringe ao lidar com uma perspectiva de "resposta certa" $e$ buscar verificar se o aluno sabe, apresentando (ou não) a resposta requerida.

Essa questão parece estar presente, justamente em termos ortodoxos, para os alunosprofessores, pois estes se manifestam afirmando que é certo a avaliação por meio de provas presenciais em que o aluno tem que atingir uma determinada nota (Aluna GRACI)... Servindo para que esse ensino não seja tão vulnerável (Aluna VAL)... Assim, dá pra comprovar se ele tem credibilidade (Aluna MASÉ).

Essas alunas-professoras demonstram acreditar que a simples aplicação de provas presenciais é garantia da qualidade e da credibilidade da ação avaliativa na educação a distância. Para Hoffman (2005:11), entre os fatores que se transformam em obstáculos à superação da prática avaliativa tradicional, desponta sobremaneira a crença dos educadores... na manutenção da ação avaliativa classificatória como garantia de um ensino de qualidade. Esse aspecto se evidencia porque as alunas não conseguem vislumbrar outras possibilidades avaliativas que atendam aos requisitos de credibilidade.

Contudo, a questão que se impõe nesse contexto, não é a de exclusão de procedimentos, deixando de adotar os exames presenciais na EAD que, em nossa cultura, é o mais comum dos instrumentos avaliativos, mas ressignificá-los para incluí-los numa perspectiva construtivista (Cf. MORETTO, 2001), a partir da qual os exames se transformam em veículo de informações significativas e qualitativas sobre as dificuldades da aprendizagem que estão se produzindo no curso mesmo do processo. Mais ainda, incluir outras possibilidades que possam constituir uma multiplicidade de recursos avaliativos a serviço do salto qualitativo da avaliação da aprendizagem a distância, representado pela ênfase no desenvolvimento do processo de formação.

Associada a outros aspectos, uma abordagem avaliativa de caráter plural e formativo na EAD poderia contribuir para a garantia de um ensino de qualidade, representando a superação da avaliação tradicional de caráter apenas classificatório que tem sido, historicamente, inábil no sentido de apontar as falhas do processo, pois negligencia as reais dificuldades dos alunos, as lacunas dos materiais didáticos e da programação de atendimento tutorial.

Por essa razão, importa considerar que a avaliação da aprendizagem precisa ser coerente com a forma de ensinar (MORETTO, 2001:96). Em outras palavras, conceber e planejar a ação avaliativa na educação, presencial e a distância, pressupõe clareza e precisão na escolha de critérios, objetivos e meios.

\section{CONSIDERAÇÕES FINAIS}

Ampliado pela discussão de situações-problema simuladas da EAD e discussões coletivas, o processo de formação sob análise serviu-nos como via de reflexão sobre a própria prática docente dos sujeitos, gerando um mecanismo que permitiu, como quer Imbernón $(2005)^{37}$, retomar suas experiências vividas, examinar suas atitudes, questionar e redimensionar sua prática profissional.

Nessa perspectiva, os alunos-professores assumiram-se como construtores de conhecimentos profissionais ligados, particularmente, à sua atuação na educação a distância.

${ }^{37}$ IMBERNÓN, F. Formação Docente e Profissional: formar-se para a mudança e a incerteza. São Paulo: Cortez. $5^{\mathrm{a}}$ ed., 2005. 
Contestando limites e distorções da concepção tradicional da prática tutorial, bem como de outros aspectos.

Enfim, aprendemos a tornar esse processo mais consistente e efetivo, quando esses sujeitos sentiram que suas experiências e vozes estavam sendo valorizadas como elementos da sua própria formação. Acredito que esse aspecto foi imprescindível para que eles se voltassem para o estudo das questões próprias da educação a distância e se assumissem efetivamente como futuros professores-tutores.

No decorrer dos encontros de formação, comprovamos o valor das interações e da troca de experiências na construção de novos referenciais para a EAD. Isso porque, ao trazerem suas reflexões, pontos de vista, questionamentos, inquietações, memórias de fatos vividos como alunos a distância, os sujeitos evidenciaram saberes tácitos, no dizer de Schön (1992), mobilizadores de novos significados e de novas práticas, que acabaram por influir no quadro conceitual da EAD.

Embora a palavra distância defina ou caracterize essa modalidade de ensino no presente, a garantia da qualidade dos processos de ensino-aprendizagem a distância está associada, justamente em termos atuais, aos mecanismos de aproximação dos sujeitos envolvidos nesse contexto formativo, sem, contudo, perder de vista a condição de ensinoaprendizagem a distância. É mais propriamente o sentido da educação que se põe em uma escola ubíqua, que passa a estar em toda parte (Cf. Siqueira, 2004).

Muito se tem dito sobre a importância do trabalho coletivo entre os profissionais atuantes na EAD (Cf. BELLONI, 2003) e da necessidade dos encontros de interação entre alunos de cursos a distância (Cf. LITWIN, 2001) ${ }^{38}$, como forma de situar numa perspectiva sócio-construtiva os processos de concepção, planejamento, execução da relação ensinoaprendizagem a distância.

Numa concepção coletiva de trabalho, o conhecimento dos professores-tutores sobre o perfil dos alunos pode enriquecer tarefas como sugestão de critérios para a definição e organização dos conteúdos de ensino, de estratégias para o intercâmbio da informação, que impliquem, segundo ressalta Litwin (2001:67), a escolha de atividades e de recursos significativos para a aprendizagem, bem como para a elaboração de instrumentos de avaliação coerentes com as concepções didáticas sustentadas.

Nessa direção, é desejável, a nosso ver, que a formação de professores a distância se realize levando em consideração de importância a complexidade do conhecimento veiculado nas situações de trabalho, explorando conflitos, receios, conquistas e expectativas. Essa perspectiva formativa, no contexto de formação trazida para análise, mobilizou reações múltiplas, particularmente, a respeito da iminência de mudança da realidade dos processos de ensino e de aprendizagem, da necessidade de perspectivas paradigmáticas emergentes e de proposições inovadoras pertinentes a avaliação da aprendizagem a distância.

\footnotetext{
${ }^{38}$ LITWIN, E. Das Tradições à Virtualidade In: LITWIN, E. (Org.) Educação a Distância: temas para o debate de uma nova agenda educativa. Porto Alegre: Artmed. Tradução de Fátima Murad, 2001. 